\title{
Horácio revisitado pelo poeta italiano Giovanni Pascoli
}

\author{
LOREDANA DE STAUBER CAPRARA \\ Departamento de Letras Modernas \\ Faculdade de Filosofia, Letras e Ciências Humanas \\ Universidade de São Paulo
}

\begin{abstract}
RESUMO: Na virada do século, o poeta italiano Giovanni Pascoli escreveu vários poemetos em latim, inspirados na poesia horaciana, tendo o próprio poeta latino como protagonista, a fim de apresentá-los aos Certamina Hoeuftiana de Amsterdam. Se os modelos, lingüístico e temático, são as obras de Horácio e de outros autores latinos, inclusive cristãos, num trabalho de fascinante intertextualidade, o tom poético é dado pelos reflexos dos sentimentos do próprio Pascoli.
\end{abstract}

PALAVRAS-CHAVE: Poesia italiana, língua latina, cultura clássica, experimentalismo lingüístico.

Pouco conhecido no Brasil, Giovanni Pascoli, entre o fim do século passado e o começo do século XX, foi um dos maiores poetas italianos. Por sua rejeição da linguagem poética petrarquesca, tradicional na Itália, e por seu experimentalismo lingüístico é considerado um dos renovadores da linguagem poética peninsular. A atenção extremada dada ao significante e a busca de uma pluralidade de significados alusivos tornam-no anticlássico, na linha do Decadentismo do fim do século XIX (Binni, 1961; Beccaria,1975).

Por outro lado, o mesmo experimentalismo lingúístico, unido à paixão pelos autores antigos, leva-o a escrever em latim, imitando os clássicos em obras que freqüentemente alcançam alto nível de poesia (Traina, 1971), numa atitude que poderia parecer incoerente para quem havia rejeitado a tradição poética e linguiística de seu país.

A nossa pergunta é a seguinte: até que ponto ele deve ser considerado fiel imitador dos clássicos como pretendem alguns críticos? (Paratore, 1965). O que permanece em seus versos da poesia de Horácio, seu maior mestre, é pura forma ou uma desesperada tentativa de alcançar o equilíbrio próprio dos clássicos? Em que aspecto ele é poeta moderno e filho de sua época decadente, mesmo em seus versos latinos?

Poeta italiano, conhecido e celebrado, Pascoli escreveu em latim os Carmina, uma coletânea de poemas publicados póstumamente na Itália, em 1913. Mas, de 1891 a 1912, todos os anos, Pascoli enviava aos Certamina Hoeuftiana de poesia latina de Amsterdam, um ou mais poemas, 
ganhando freqüentemente o primeiro prêmio: uma medalha de ouro e a publicação em fascículos especiais. Deste modo, tornou-se famoso na Europa como poeta em latim, capaz de recriar todo o encanto dos clássicos num tom inconfundível. O próprio Saussure, reconhecendo em sua poesia latina ecos e técnicas comuns nos autores antigos e particularmente em Vergílio, dirigiu-se a ele para esclarecimentos sobre o que definia como "palavras-tema", geradoras de hipogramas e anagramas, palavras-indutoras de variações fônicas e de poesia, numerosas nos poemas pascolianos, bem como na poesia clássica. Saussure pensava que o processo criador que despertava seu interesse pela regularidade e pelos efeitos sugestivos fosse consciente e que Pascoli o tivesse reconhecido nos textos clássicos e imitado de propósito (Starobinski, 1974, p. 104-6). As respostas de Pascoli não foram encontradas, talvez porque nunca tivessem sido escritas. Provavelmente, a poesia pascoliana procedia por variações fônicas de modo intuitivo, a partir de determinadas palavras temáticas. O jogo das variações, como a intertextualidade, são característicos da poesia; a estranheza pascoliana, se assim pode ser considerada, limita-se à regularidade e à insistência do fenômeno notado por Saussure. Num outro plano, pode causar estranheza o uso da língua latina em época moderna, por um poeta que se pretendia inovador.

Mas, a este respeito, talvez seja importante nos aprofundarmos no conceito que Pascoli tinha do latim como língua de poesia. Quanto aos concursos de Amsterdam, foram apenas uma ocasião para libertar seu desejo de expressão numa língua na qual o significante poderia ter um peso maior do que em italiano, vista a dificuldade do leitor em alcançar o significado. O latim pascoliano é rico em alusões e sugere significações que os poemetos não declaram explicitamente. O latim, para Pascoli, é a "língua morta" que seus poemas fazem reviver, é a língua secreta das premonições de morte e da esperança de sobreviver (Pascoli, 1956, p. 155). Às vezes tem, também, outras significações, mais secretas ainda. É, outrossim, o instrumento que permite dialogar com poetas queridos, velhos amigos ainda vivos, apesar de uma morte de dois milênios, não só nas obras que escreveram na antigüidade e que continuam sendo lidas, mas também como personagens das obras pascolianas, aos quais emprestam suas palavras: conceitos todos ligados à postura decadente do poeta, na linha do Decadentismo europeu fin de siècle.

É evidente que Pascoli não apenas estudou profunda e apaixonadamente os poetas latinos (Pascoli, 1934), em primeiro lugar Catulo, Vergílio e Horácio, dos quais repete, com variações, palavras e versos, e transformando esses mesmos poetas em personagens de suas histórias, identificou-se com eles, a fim de continuar, dessa forma, o diálogo iniciado na mocidade, com a primeira leitura de obras que tanto o marcaram. Mas a sua não é uma leitura crítica e objetiva, é interiorizada e emocionada, guiada pela interpretação subjetiva de palavras e frases, isoladas de seu contexto, e transformadas em algo que dificilmente os poetas antigos teriam dito.

Não se quer diminuir com isso a cultura latina de Pascoli, profunda e muito extensa. Durante muitos anos ele foi docente de língua e literatura latina em universidades prestigiosas, conhecia pormenorizadamente obras de toda a latinidade, inclusive cristã, medieval e humanista. Mas com os poetas mencionados tinha uma ligação diferente, mais envolvente e pessoal.

Ao ler Horácio, Catulo, Vergílio, revive com eles uma vida antiga e imagina a realidade que se estende além das palavras escritas. É assim que consegue retomar alguns episódios por eles narrados, para desenvolvê-los a seu modo. Pascoli costuma iniciar seus poemas latinos repetindo as palavras do próprio poeta antigo, o qual, muitas vezes, torna-se protagonista. Ao redor é recriado o ambiente dos contemporâneos e amigos, num collage fascinante, cujo conjunto, apesar dos muitos elementos autênticos, é obra original e moderna por sentimento e imaginação.

Por exemplo, o poemeto Phidyle (1893), que canta a vida rústica, repetindo frases e expressões horacianas, inicia:

\section{O fons Bandusiae gelidis qui reddere rivis}

retomando o famosíssimo: 


\section{O fons Bandusiae splendidior vitro (Hor. Od. III.13)}

e termina:

\section{Illa manus intenta tenet, tenet ora sub auris}

que relembra:

caelo supinas si tuleris manus/ ...rustica Phidyle (Hor. Od. III.23)

Citei apenas dois versos desse poemeto, mas poderia mencionar muitos outros que o poeta extrai de várias obras horacianas para dar autenticidade ao seu quadro. No entanto, apesar da proximidade com os textos horacianos, o poemeto de Pascoli tem seu centro de interesse na delicadeza, afetividade e religiosidade da figura feminina. Reconhecemos nela, mais matizada, uma figura dos poemas italianos da mesma época (Primi poemetti, 1897-1904), por ser a transfiguração poética da irmã do poeta. Não é o caso, neste contexto, de enfrentar pormenorizadamente o assunto das ambigüidades do relacionamento entre os irmãos Pascoli e dos traços desse sentimento nas obras do poeta (Pascoli, 1985, p.76-84). Mas é evidente que as reminiscências literárias e o uso do latim escondem e revelam algo muito pessoal, estranho à cultura clássica e, entretanto, ligado a ela, quer pela idealidade cultural e espiritual que subentende, quer pelo afastamento temporal que tira da representação as lembranças contingentes. A poesia tem suas raízes no fundo da alma e, se freqüentemente é gerada por outra poesia, isso por si só não lhe proporciona qualidade; de outro lado, para se tornar poesia verdadeira, tem de evitar aproximações demasiadamente fieis à realidade vivida.

Um dos aspectos originais da poesia pascoliana é que, usando palavras antigas, Pascoli não só permanece um homem moderno mas, espelhando-se nos antigos, torna-os, também eles, modernos por emprestar-lhes suas angústias e seus sentimentos mais secretos. Original é a procura das dulces latebrae, isto é, do recesso sereno da poesia antiga, como estímulo para a produção de nova poesia moderna em língua antiga. Original é a sublimação da angústia, que, se às vezes na poesia italiana de Pascoli se derrama em lamentos, em latim, compensada pela esperança de sobrevivência, se manifesta apenas indiretamente. $O$ desespero da morte, $O$ desequilíbrio existencial, o sofrimento, paradoxalmente, dão vida às reminiscências clássicas, mas, ao mesmo tempo, essas reminiscências constituem uma pausa feliz no recesso da memória, que torna mais leve o fardo pesado da vivência pascoliana.

Então, para Pascoli, apesar da língua latina ter conotações simbólicas e apresentarse como um disfarce para mostrar as contradições de um espírito atormentado e dolorido, a poesia latina antiga, em sua compostura clássica, é percebida como elemento de equilíbrio. Eé, principalmente, na poesia de Horácio que Pascoli encontra essa função equilibradora. Horácio é o mestre que, desde suas primeiras provas em latim, Pascoli evoca, com quem dialoga, de quem recebe conselhos. Diz o poeta italiano num de seus primeiros poemas nessa língua:

volucri mente sequor tamen / vatemque in latebris dulcibus adloquor - com o pensamento ligeiro vou atrás do poeta e falo com ele em seu doce recesso.

E o poeta antigo responde:

Magna memor fuge - lembre-se de evitar as coisas grandes.

(Iani Nemorini Silvula)

Como dulces latebrae, também fuge magna é expressão horaciana (Ep.1.10.32), pascoliano é o memor, palavra temática para indicar tanto a memória quanto a consciência. O poeta moderno deve lembrar as palavras do antigo e, ao mesmo tempo, modernamente deve ter consciência de si mesmo.

Com facilidade Pascoli mergulha na profundeza dos séculos, como num transe que, embora negue o equilíbrio clássico, lhe permite participar da vida dos antigos: 


\section{Oblita videor tum veterem mente resumere / vitam}

então parece-me reencontrar no pensamento a vida passada. (Poematia, 221)

A técnica, poética e lingüística, - como já foi dito - é de isolar, nos textos antigos, palavras e expressões a serem reutilizadas com variações, em contextos diferentes. Facilmente essas palavras, quando empregadas por Pascoli, assumem outros significados, afastados daqueles que possuíam nos textos originais.

Às vezes Pascoli usa frases completas de seus mestres para expressar a sua própria visão de vida e de poesia: Non omnis moriar, - repete com Horácio (Od.III,30), mas, alicerçado na sua pessoal visão da poesia, acrescenta -

si quid olet novum, / si quid silva sonat non aliis prius / auditum....

(Não vou morrer completamente,) se algo novo espalhará seu perfume, se algo nunca visto antes ressoará na selva....

(Iani Nemorini Silvula)

Em comparação com o orgulho horaciano, a sua é uma visão humilde da poesia, ligada à natureza, à vida do campo, aos ciclos naturais que sempre reaparecem em seus versos como outra forma de imortalidade. O Non omnis moriar multaque pars mei é uma frase que poderíamos definir temática da poesia pascoliana, não apenas em latim. Em latim, frequientemente, é pronunciada por Horácio, mas outras vezes são personagens cristãos a dizê-la e, então, assume um sentido totalmente diferente daquele que lhe havia atribuído o poeta latino. Nos poemetos em que Horácio é protagonista, pode acontecer que ele repita suas próprias palavras de outrora como se refletisse sobre elas querendo corrigi-las, tornando-as mais próximas de um novo pensamento que está se formando em sua mente e que corresponde à visão do poeta moderno.

Non omnis moriar! Quin pars mihi multa...

Quid? Omnis,

omnis ut es, Publi, tibi, ero mihi ego ipse superstes!

Não vou morrer completamente! Grande parte de mim... O que? sobreviverei completamente assim como você, Vergílio, completamente sobrevive.

\section{(Ultima linea, 106-7)}

Parece que aqui Pascoli se refere a uma sobrevivência pessoal, à sobrevivência da alma o segundo e o terceiro omnis referem-se à alma imortal - o conceito é muito diferente daquele do poeta clássico, e há hesitação e consciência da ousadia, expressas pela repetição e pela fragmentação sintática da frase.

A mesma citação do Non omnis moriar, repete-se passando de obra em obra, sempre levemente modificada, até se tornar quase irreconhecível:

Me quoque, rive, doce, perlucide qui nigris sub umbris

hinc semper is, hic semper es, perennis.

$O$ utinam, similis plane tibi, laberer, manerem! et unda frondes ferret atque flores,

non vocem, non hoc murmur leve, quod viator edo, non quae mei pars maior est et omni

non cantum, quem, rive fugax, canis, ut cano fatigans

ad saxa fluctus labilemque vitam.

Ensine-me, ó riacho cristalino, você que perenemente, debaixo de sombras escuras, sempre corre e sempre permanece. Ỏ se eu também, parecido com você, pudesse passar e permanecer! e a água levasse as folhas e as flores, mas não a voz, não esse 
leve murmúrio que solto em minha passagem, não a parte de mim que é maior de tudo, não o canto - que você canta, riacho fugitivo, como eu canto, cansando-me contra as pedras e a corrente da vida que se desfaz.

(Fanum Vacunae, 253-6)

Se, nesses versos de 1910, Pascoli volta a pensar na sobrevivência mediante a poesia, trata-se agora de uma poesia que não é mais somente o canto do poeta sobre a natureza como na Jani Nemorini Silvula (1892), ou em alguns versos de Myricae (1891), mas é também o canto da própria natureza imortal. O poeta confunde sua voz com a voz do rio que passa e permanece, sempre igual, apesar do trancorrer do tempo.

Dissemos que Horácio é para Pascoli o modelo preferido, a personagem que mais freqüentemente retorna em seus poemetos latinos. Mas há um desses poemetos que merece destaque pelo tratamento dado à personagem: Ultima linea. Em Ultima linea, Pascoli identificase a tal ponto com o poeta protagonista que sentimos, por detrás do mosaico de citações horacianas, a autobiografia do homem do século XX, com sua postura decadente, sua angústia psicologizada, seus problemas religiosos irresolvidos, seus medos e seu ceticismo irredutível.

Composto em 1906, o poemeto foi premiado em Amsterdam com medalha de ouro. A começar pelo título - Ultima linea - que retoma um verso da $16^{\mathrm{a}}$ Epístola horaciana do $1^{\circ}$ livro: ...mors ultima linea rerum est..., o poemeto é uma "colcha de retalhos" no qual se destacam versos horacianos de várias Epístolas, Odes e Sátiras, a que devem ser acrescentadas reminiscências de alguns versos das Bucólicas de Vergílio (Ecl. IV), citações de Isaías (XI,6) e do Evangelho (Mateus, 3.3.).

O protagonista é Horácio, que se encontra em Roma, depois de um período passado em sua villa sabina, no outono de 8 a.C. Mecenas havia acabado de morrer e Horácio sente, também, a proximidade da morte. Há um vento frio e as folhas caem. Presságio do fim iminente. O poeta sente-se perturbado e não reconhece mais o ambiente ao seu redor que, outras vezes, lhe era familiar. Num estado de espírito confuso, repensa momentos de sua vida, relatados na poesia: $o$ Lucrétile, o camponês Cérvio, Fídyle que agora deve ser uma mulher, o pequeno templo da deusa Vacuna, a fonte Bandúsia. É o mundo da poesia horaciana, mas é também o mundo que o próprio Pascoli retratou, inspirando-se naquela mesma poesia. Há em Pascoli "a necessidade de evocar continuamente a poesia própria e a de outrem, para trazer de volta estados de alma, idéias, conceitos". Assim, começa a identificação entre os dois poetas: o antigo como personagem com seu nome e seus versos e o moderno com seu espírito e sua problemática. "Confusão de duas consciências em duas diferentes idades históricas?", pergunta-se Goffis (Goffis, 1969, p. 208), um dos intérpretes que mais a fundo procurou investigar no emaranhado de significações da produção pascoliana em latim.

Horácio é retratado aos 51 anos, na véspera da morte - com efeito, ele virá a falecer em 27 de novembro daquele mesmo 8 a.C. -, Pascoli também tem 51 anos quando escreve o poema e desde sempre é obcecado pelo pensamento da morte (que ocorrerá mais tarde, aos 56 anos, em 1912). Mas o poemeto pascoliano é de 1906: o ano da morte de outro mestre de Pascoli, o poeta Carducci. A Carducci Pascoli estava ligado por profunda amizade desde os anos de estudo na universidade de Bolonha, e - há um outro motivo de identificação - agora vai substitui-lo, na cadeira de Literatura Italiana, da mesma universidade.

O jogo das identificações amplia-se e complica-se num labirinto de sensações e palavras, reflete-se no poemeto como um pesadelo. Percebemo-lo no desconforto inicial e particularmente na parte final, quando Horácio, em seu passeio, envereda pela via Sacra e, como da outra vez (Hor. Sat.I, 9), encontra o amigo Fusco Arístio. Os dois conversam lembrando o episódio narrado na sátira, até que, a certo momento, Fusco, percebendo a angústia do amigo, procura reanimá-lo:

Utor amicis / Iudaeis, ut scis. Dicunt iam tempus adesse / quo princeps pacis 
sancta de virgine, quo rex / nascatur mundi. Vox per deserta locorum / quae iubeat sternique vias et vasa parari / auditur. Tum mella fluent, ac pardus et haedus / pascenturque simul vituli catulique leonum.

Entre meus amigos há alguns judeus, você sabe. Dizem que se aproxima o dia em que de uma virgem pura vai nascer o príncipe da paz, o rei do mundo. Ouve-se uma voz no deserto que fala para preparar os caminhos, para estarmos prontos. Então fluirão rios de mel, e a onça e o cabrito, os bezerros e os filhotes dos leões pastarão juntos.

(Ultima linea, 132-7)

O mundo clássico e os mundos da nossa fé (o Velho e o Novo Testamento) são aproximados, pois simbolizam os dois mestres que o poeta moderno sente como parte de si e de sua formação espiritual. No final do poemeto vemos que a esperança da fé não vinga. Pascoli não é religioso, apenas sente o valor das tradições como parte integrante de sua cultura. $O$ que vai lhe sobreviver é a poesia.

Em Horácio, Pascoli vê a si próprio e, identificando-se nele, acentua os aspectos que coincidem em suas vidas. Mas, além das coincidências, há diferenças tão grandes que temos de concordar com os críticos que definem Pascoli como anti-clássico, apesar do uso refinado e competente que faz de palavras clássicas. $O$ fato de reelaborar com extrema elegância textos antigos, juntando-os com outros de origem e épocas diferentes, e de usar as figuras dos poetas latinos como protagonistas de suas histórias, identificando-se neles, não diminui a distância que os separa, apenas confirma o amor apaixonado por esses poetas, o estudo e o domínio de suas obras a ponto de poder usar as palavras de seus textos com espontaneidade e leveza. Pascoli domina o jogo das palavras. Gosta de recriar textos alheios, modificando-lhes o sentido. Não faz isso apenas com os clássicos latinos, mas também com poemas simbolistas. Por exemplo em $I l$ transito (Primi Poemetti) repete com grande habilidade técnica expressões e imagens de Mallarmé (Le vierge, le vivace et le bel aujourd'hui). No entanto falta neste elegante poema a empatia que existe nos versos latinos e sua leitura não nos sensibiliza tanto. A técnica é elemento importante da poesia, mas não é qualidade suficiente.

Então perguntamos novamente: o que encontrou Pascoli nos poetas latinos que escolheu como modelos? É uma certa idéia de classicismo ou é o seu contrário: uma identificação acrítica, baseada num estudo apaixonado e na ressonância em seu espírito de algumas palavras, frases, imagens, de algum ritmo ou de alguma melodia? Com esses elementos ele cria, à maneira dos artistas pós-modernos, obras que, em seu conjunto, pouco têm a ver com os modelos utilizados, mas que, de qualquer forma, espalham ao seu redor um perfume inconfundível, nascido da memória e da saudade dos clássicos.

O uso da língua latina, "língua morta", como ele a define, e o jogo com as palavras de outros poetas, de Horácio em primeiro lugar, tornam-se elementos simbólicos: ao mesmo tempo morte e sobrevivência, permanência neste mundo além dos limites consentidos, em formas sempre renovadas. Isso ocorre porque aquela poesia está viva em seu espírito. É uma paixão, e é paixão idealizada. Apesar de tudo, o emaranhado desses sentimentos contrastantes gera um equilíbrio, cria uma esperança; e, como consequência, proporciona à expressão delicadeza e leveza. Aquela leveza que, para Calvino, é uma das qualidades mais fascinantes da poesia que vale a pena guardar para o século XXI (Calvino, 1989).

De fato, as palavras, isoladas de seus contextos, libertadas das ligações de outrora, relativas ao sentido e à sintaxe, tornam-se mais leves, reconhecíveis e, ao mesmo tempo, diferentes no contex to em que agora as encontramos, ao ponto de não deixar transparecer totalmente o peso do desespero de quem, repetindo-as em seu próprio texto, acolhe a suavidade de outros textos e de outra época. De consolatione poesiae, poderíamos sugerir, parafraseando um título famoso, se bem que a visão consolatória seja considerada obsoleta, mas, para Pascoli, ela parece ser uma sugestão inevitável. 
Voltando a Calvino, das outras qualidades da literatura que vale a pena guardar para 0 próximo milênio, quais pertencem a Pascoli, pelo menos ao Pascoli latino? Penso na visibilidade e na multiplicidade. As personagem pascolianas: Horácio, Vergílio, Catulo em primeiro lugar, mas também algumas figuras menores e também as criações do poeta, totalmente imaginárias, são retratadas em atitudes que as fazem surgir diante de nossos olhos, vivas e inesquecíveis. E cada uma delas tem sua voz particular, semelhante ou não a vozes antigas; no conjunto, temos uma multiplicidade de vozes, vindo de autores diferentes, que se encontram, se entrelaçam, se repetem em múltiplas variações, sem perder a identidade original que the vem dos textos antigos, mas expressando as facetas do mundo moderno num jogo de espelhos no qual se encontram antigüidade e modernidade, clareza e ambigüidade, sob o sorriso de Horácio, levemente zombeteiro.

\section{Referências Bibliográficas}

PASCOLI, G. Carmina. Milano: Mondadori,1970.

PASCOLI, G. Poesie. Milano: Mondadori, 1981.

PASCOLI, G. Un poeta di lingua morta. In: Prose. Milano: Mondadori, 1956.

PASCOLI, G. Lyra. Antologia della poesia lirica latina. Introduzione di G. Pascoli. Firenze: Giusti, 1934.

PASCOLI, G. Poesie famigliari (a cura di Cesare Garboli). Milano: Mondadori, 1985.

ORAZIO. Odi ed Epodi. Bologna: Zanichelli, 1959.

ORAZIO. Satire. Milano: Rizzoli, 1981.

MALLARMÉ, S. Poésies / Poesie. Milano, Feltrinelli, 1983.

BECCARIA, G.L. L'autonomia del significante. Figure del ritmo e della sintassi: Dante, Pascoli, D'Annunzio. Torino: Einaudi, 1975.

BINNI, Walter. La poetica di G. Pascoli. In: La poetica del Decadentismo. Firenze: Sansoni, 1961. CALVINO,I. Lezioni americane. Sei proposte per il prossimo millennio. Milano: Garzanti, 1988.

GOFFIS, C. Pascoli antico e nuovo. Brescia: Paideia, 1969.

PARATORE, E. La poesia latina del Pascoli. In:Antico e Nuovo. Roma: Sciascia, 1965.

STAROBINSKI, J. As palavras sob as palavras. São Paulo: Perspectiva, 1974.

TRAINA, A. Il latino del Pascoli. Firenze: Le Monnier, 1971.

CAPRARA, Loredana de S. Horace revisiteé par le poète italien Giovanni Pascoli. Classica, São Paulo, 7/8: 309-315, 1994/1995.

RÉSUMÉ: Entre les XIXe et XXe siècles, le poète italien Giovanni Pascoli écrit plusieurs poèmes en latin inspirés de la poésie horacienne, pour les presenter aux Certamina Hoeuftiana de Amsterdan, ayant comme protagoniste le même Horace. Si les modèles, linguistique et thématique, sont les oeuvres de Horace et d'autres auteurs latins y compris les chrétiens, dans um travail de fascinante intertextualité, le ton poétique est donné par les reflets des sentiments de Pascoli lui-même.

MOTS CLÉS: Poésie italienne, langue latine, culture classique, expérimentation linguistique. 